National Energy Technology Laboratory

Strategic Center For Natural Gas (SCNG)

\title{
Acoustic Detecting and Locating Gas Pipe Line Infringement $3^{\text {rd }}$ Quarterly Report
}

Reporting Start Date: January 1, 2003

Reporting End Date: March 30, 2003

Principle Authors:

John L. Loth (304) 293-4111 ext 2343

jloth@mail.wvu.edu

Gary J. Morris (304) 293-4111 ext 2342

gmorris@mail.wvu.edu

(Mike) George M. Palmer (304) 293-4111 ext 2342

gmpalmer@mail.wvu.edu

and graduate students:

Richard Guiler and Deepak Mehra

Report Issue Date: April 1, 2003

DOE Award Number: DE-FC26-02NT41324

\author{
Submitting Organization: \\ West Virginia University \\ Department of Mechanical and Aerospace Engineering \\ G-70 Engineering Sciences Building \\ Evansdale Drive \\ Morgantown, WV 26506 \\ SCNG Contact: \\ Daniel J. Driscoll (304) 285-4717 \\ daniel.driscoll@,netl.doe.gov \\ Industrial Contact: \\ Brian C. Sheppard (304) 627-3733 \\ Brian_C Sheppard@dom.com \\ At Dominion Transmission, Inc
}




\section{Table of Contents}

Abstract 3

Executive Summary $\quad 4$

I. Introduction 5

$\begin{array}{ll}\text { II. Experimental } & 7\end{array}$

A. Microphones $\quad 7$

B. Data Acquisition 11

C. Signal Processing $\quad 12$

III. Results and Discussion $\quad 17$

IV. Conclusions 19

$\begin{array}{ll}\text { V. References } & 20\end{array}$

VII. Appendix 1 - Diaphragm operating characteristics 21

\section{List Tables}

Table 1 - Brüel\&Kjær model 4133 condenser microphone specifications.

Table 2 - Brüel\&Kjær model 4134 condenser microphone specifications.

Table 3 - DAQP-208H Specifications.

Table 4 - Center and cutoff frequencies $(\mathrm{Hz})$ for standard full octave and $1 / 3$ octave filters.

\section{List of Figures}

Figure 1 - Dominion line 323 near Morgantown, WV, the $1 / 2$ " NPT inspection ports can be seen located on either side of the shut-off valve.

Figure 2 - Acoustic Sensor for 300-psi gas pipeline with source /sink type aerodynamic signal amplifier

Figure 3 - Sectional view of Model 4133 and 4134 microphone cartridges.

Figure 4- Shows typical dynamic ranges of microphone and preamplifier assembly combinations.

Figure 5- Typical frequency responses of the different pressure response microphones recorded by means of the electrostatic actuator method.

Figure 6- Typical $0^{\circ}$ incidence free-field frequency responses of the different free-field microphones recorded by means of the electrostatic-actuator method.

Figure 7 - Free field corrections for the B \& K model 4133 and 4134 microphones operating characteristics.

Figure 8 - Characteristics of an octave band filter.

Figure 9 - Complete filter characteristics for a typical octave band filter set.

Figure 10 - Non-dimensional diaphragm pressure distributions.

Figure 11 - Diaphragm force amplification.

Figure 12 - Air-flow rate vs. dB.

Figure 13 - Diaphragm force vs. $-\mathrm{dp} / \mathrm{dt}$.

Figure 14 - Outlet velocity vs. - dp/dt. 


\title{
Disclaimer
}

"This report was prepared as an account of work sponsored by an agency of the United States Government. Neither the United States Government nor any of their employees, makes any warranty, express or implied, or assumes any legal liability or responsibility for the accuracy, completeness, or usefulness any information, apparatus, product, or process disclosed, or represents that its use would not infringe privately owned rights. Reference herein to any specific commercial product, process or service by trade name, trademark, manufacturer, or otherwise does not necessarily constitute or imply its endorsement, recommendation, or favoring by the United States Government or any agency thereof. The views and opinions of the authors expressed herein do not necessarily state or reflect those of the United States Government or any agency thereof."

\begin{abstract}
The West Virginia University natural gas transmission line leak detection research is only considering using readily available $1 / 2$ " pipeline access ports for the detection of leak generated signals. The main problem with leak signals is the low signal to noise ratio. One of the acoustic signals associated with gas escaping through a leak is only temporary and is in the form of a rarefaction wave originating when the leak is formed. Due to pipeline friction, over distance such a step function transitions to a ramp function. The ability to identify a leak by pipeline monitoring and signal processing depends a great deal on the quality and signal to noise ratio of the characteristics of the detectors used. Combinations of sensing devices are being used for the WVU sensor package and are contained in a removable sensor housing. The four sensors currently installed are a $1 / 2 " 3$ $\mathrm{Hz}-40 \mathrm{Khz}$ microphone, an audible range moving coil sensor, a piezo-electric pressure transducer, and the WVU designed floating 3" diameter diaphragm to detect flow transient induced pressure ramp type signals. The WVU diaphragm sensor, which is currently under development, uses the same diaphragm principle as a high quality capacitance type microphone, but utilizes aerodynamic signal amplification. This type of amplification only amplifies the ramp-signal itself, not the random pipeline noise.
\end{abstract}




\section{Executive Summary}

The research at WVU for the $3^{\text {rd }}$ quarter is concentrating on detecting and positively identifying gas pipeline leaks from fixed sensor locations. Only readily available pipeline access ports are being considered, such as the 1/2" NPT inspection ports located at either side of most in-line shut-off valves. The main problem is the low signal to noise ratio. One of the acoustic signals associated with gas escaping through a leak is only temporary and is in the form of a rarefaction wave originating when the leak is formed. Due to pipeline friction, over distance such a step function like pressure transient transitions to a ramp function. Similar ramp signals are produced inside branch lines by fluctuating consumer demands. The ability to identify a leak by pipeline monitoring and signal processing depends a great deal on the quality and signal to noise ratio of the characteristics of the detectors used. A wide range of detectors, filters and analyzers are commercially available. Combinations of sensing devices are being used for the WVU sensor package and are contained in a removable sensor housing. The four sensors currently installed are:

1) A 0.5 inch diameter B \& K model 4133 microphone, $3 \mathrm{~Hz}-40 \mathrm{Khz}$

2) A mono phono-graph moving coil sensor, audible frequency range

3) A Piezo-electric pressure transducer with a max reading of $400 \mathrm{psi}$

4) The WVU designed floating 3" diameter diaphragm to detect flow transient induced pressure ramp type signals.

The research at WVU is currently concentrating on developing acoustic ramp-signal sensors with aerodynamic signal amplification. The advantage of aerodynamic signal amplification is that it does not amplify random pipeline noise but only the ramp-signal itself.

One solution found is the use of a rigid container connected to the pipeline by three items: a small needle valve and in parallel with it two small spring loaded check valves mounted for flow in opposite directions. They limit the pressure difference between the container and the pipeline to their set value, for example \pm 1 psi. The passage of any ramp function inside the pipeline will produce a proportional pressure differential between the container and the pipeline, which can safely be measured by a \pm 1 psi differential pressure commercial available transducer. This allows detecting pipeline pressure transients down to 10 Pascal per second!

Another solution under development uses the sensor housing itself as the rigid container above and replaces the commercial available differential pressure transducer mentioned above with a new aerodynamic signal amplifier now under development. It utilizes the same diaphragm principle as a high quality capacitance type microphone. However the microphone uses acoustic pressure to deflect a diaphragm. Its change in capacitance is measured with an oscillator circuit. The microphone is limited to detecting signals at frequencies above $1 / 4$ Hertz. Measure of the diaphragm deflection as a change in capacitance provides a more sensitive signal. 


\title{
$\underline{3^{\text {rd }} \text { Quarterly Progress Report }}$
}

\author{
April 1, 2003 by \\ West Virginia University \\ Project: DE-FC26-02NT41324
}

\section{Topic: \\ Instrumentation Development for Detection of a Leak in a Natural Gas Transmission Pipeline}

\section{Introduction}

This research at WVU is concentrating on detecting and positively identifying gas pipeline leaks from fixed sensor locations. Only readily available pipeline access ports are being considered, such as the $1 / 2$ " NPT inspection ports located at either side of most in-line shut-off valves, Figures 1. In the January 5, 03 WVU Report on "Literature Review" it has been shown that research of this type has been under investigation for more than thirty years. The main problem is the low signal to noise ratio. Recently a few investigators claim to have successfully developed the necessary instrumentation and signal processing to market their technology at a high cost per mile of pipeline. They indicate the need to use at least two independent leak-indicating signals in order to minimize false alarms. One of these is the acoustic signal associated with gas escaping through a leak in the pipe wall. Only a portion of this acoustic signal, which occurs in the low frequency range, is capable of traveling the distance between pipeline access ports, prior to attenuation. The other signal is only temporary and is in the form of a rarefaction wave originating when the leak is formed. Due to pipeline friction, over distance such a step function like pressure transient transitions to a ramp function. Similar ramp signals are produced inside branch lines by fluctuating consumer demands. The ability to identify a leak by pipeline monitoring and signal processing depends a great deal on the quality and signal to noise ratio of the characteristics of the detectors used.

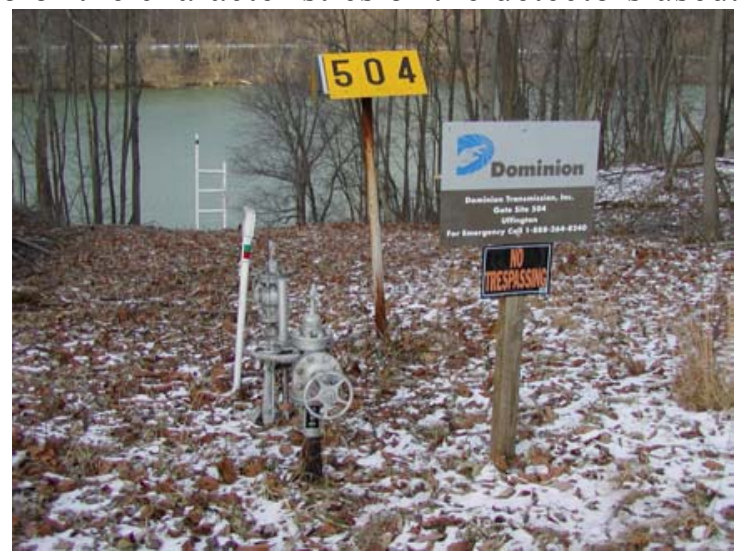

Figure 1 - Dominion line 323 near Morgantown, WV, the $1 / 2$ " NPT inspection ports can be seen located on either side of the shut-off valve. 
A wide range of detectors, filters and analyzers are commercially available. This includes highly sensitive capacitance type microphones and piezo-electric type pressure transducers. Proper venting of both sides of the sensor's diaphragm is critical to their survival when subjected to transmission pipeline pressures, which locally range up to 4000 psi. The sensitivity of sealed pressure transducers is usually limited to $10^{-3}$ of fullscale reading. Thus when placed in the pipeline they are not sensitive enough to be useful.

Combinations of sensing devices are used for monitoring and are contained in a removable sensor housing, Figure 2 . The four sensors currently installed are:

1) A 0.5 inch diameter B \& K model 4133 microphone, $3 \mathrm{~Hz}-40 \mathrm{Khz}$

2) A mono phono-graph moving coil sensor, audible frequency range

3) A Piezo-electric pressure transducer with a max reading of $400 \mathrm{psi}$

4) The WVU designed floating 3" diameter diaphragm to detect flow transient induced pressure ramp type signals.

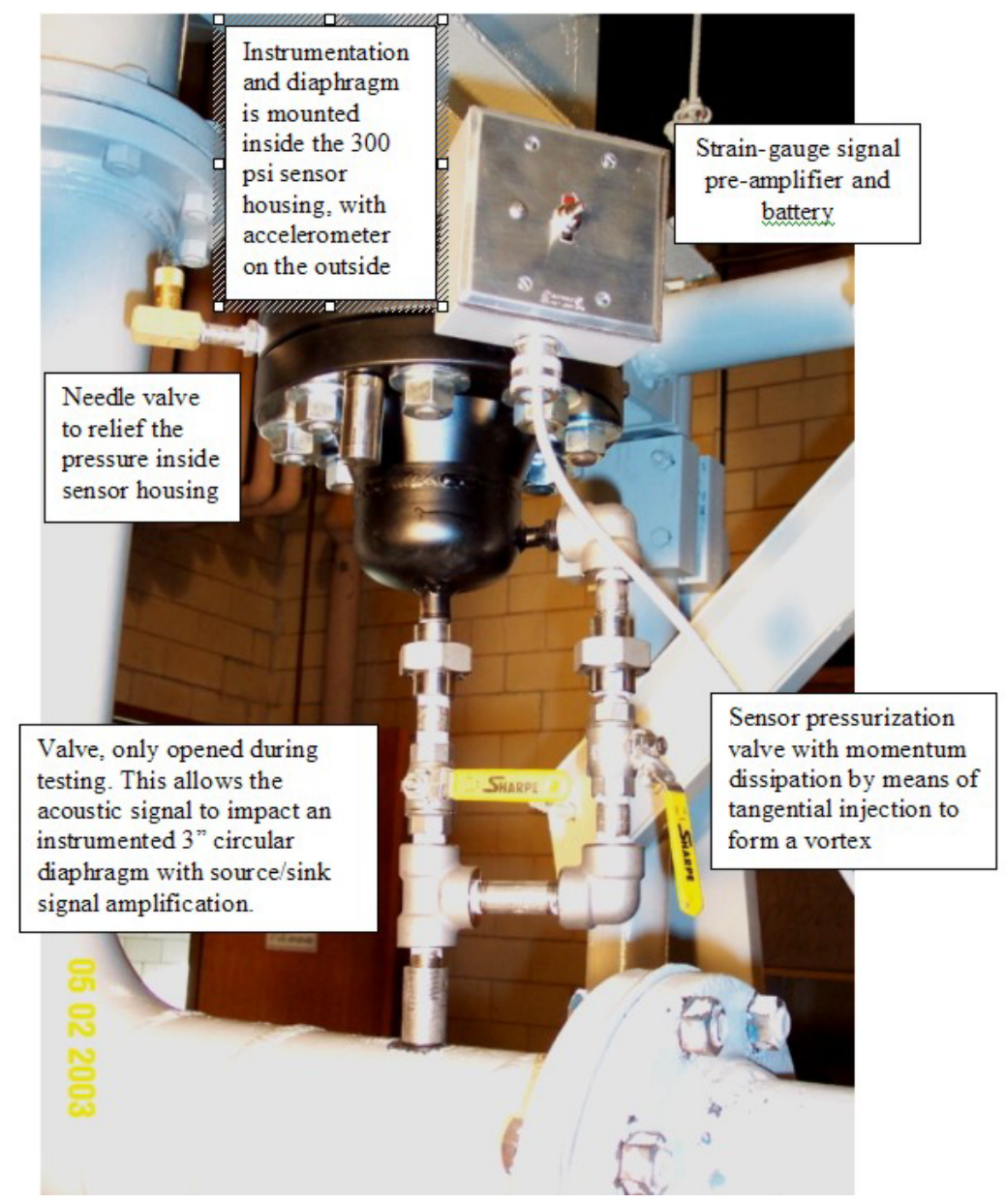

Figure 2 - Acoustic Sensor for 300 psi gas pipeline with source/sink type aerodynamic signal amplifier

All sensors are hooked up to pre-amplifiers included in the Omega Model DAQP-208H data acquisition system for laptop PC use. 


\section{Experimental}

\section{A. Microphones}

The measurement of the higher frequency portion of the pressure impulses entering the WVU sensor housing will be done using Brüel\&Kjær model 4133 and 4134 condenser microphones. Brüel\&Kjær condenser microphones. The basic operating principle for a condenser microphone is: a thin diaphragm and the fixed back plate, separated by a thin air gap, which forms the two plates of a capacitor. Pressure fluctuations from incoming sound waves cause the diaphragm to vibrate, changing the air gap. This changes the capacitance, which is measured electronically and converted into a voltage by appropriate circuitry, usually contained in a separate preamplifier. These instrumentation grade microphones are specially designed to have negligible sensitivity to temperature and humidity, and have excellent long term stability are precision engineered from materials selected to give long term stability and operational reliability. Their robust construction makes them easy to handle in the field.

These microphones have an insulator made of silicone-treated quartz, the diaphragm consists of nickel and the back plate and housing are made of high nickel alloys. This minimizes variations in sensitivity with temperature. Microphone components are shown in Figure 3. The microphones require an electric field to be present between the back plate and the diaphragm. The model 4133 and 4134 microphones are externally polarized microphones, which obtain the charge for the electric field from a DC power supply connected to the microphone via the preamplifier. Charge build-up the back plate is not instantaneous, due to the high charge.

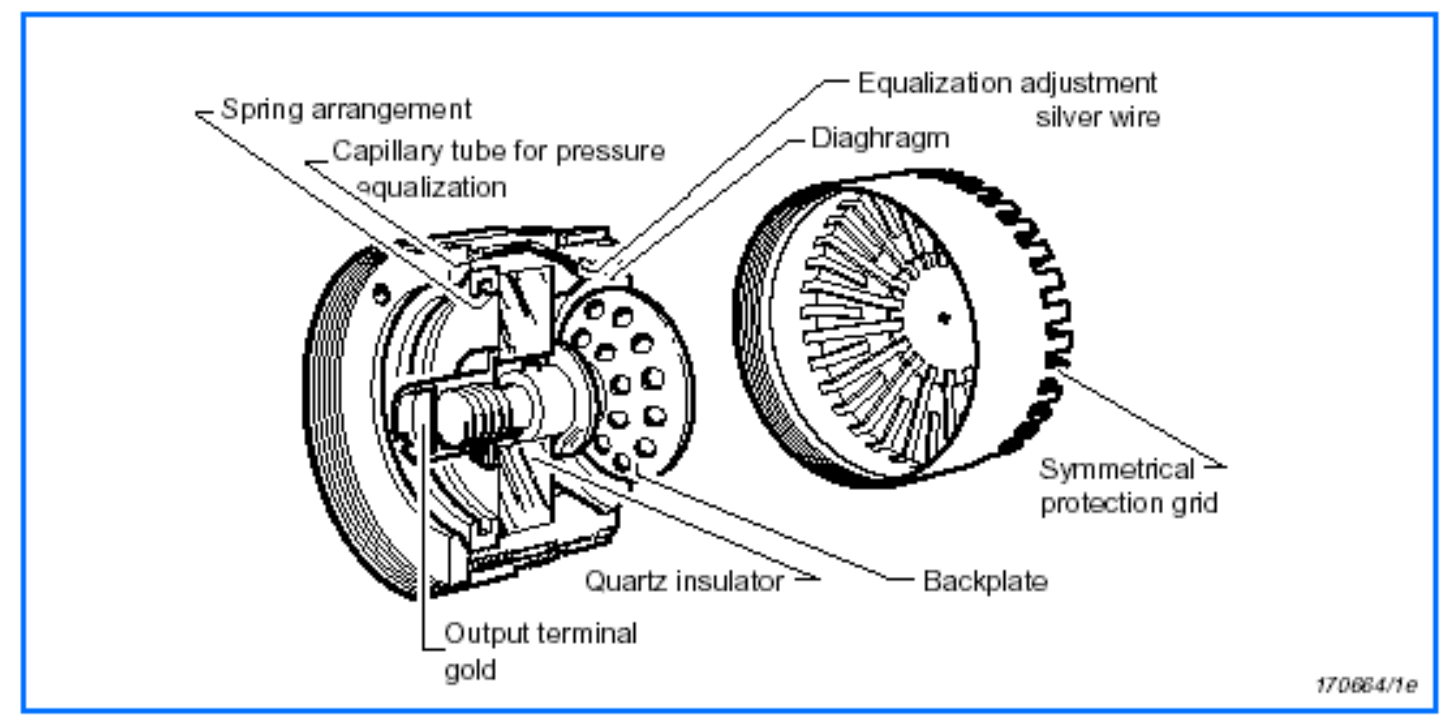

Figure 3 - Sectional view of Model 4133 and 4134 microphone cartridges (Brüel\&Kjær, 2002).

There are a variety of preamplifiers that can be used with these microphones. The preamplifiers are as follows: 1) Type 2639, 2) Type 2645 is a 1/2" preamplifier which is 
similar in design, performance and application to the Type 2639, but also includes an insert-voltage calibration facility for insert-voltage calibration of 1/2" microphones in accordance with IEC327 and ANSI S1.10-1966. The preamplifier may be operated in either driven or grounded shield modes. 3) Type $\mathbf{2 6 6 0}$ has been specially developed as part of a low-noise microphone system for $1 / 2$ " microphones and 4)Type 2669.

The stabilized polarization voltage for the microphone cartridges $(200 \mathrm{~V})$ and the power supply for the microphone preamplifiers are available via the 7-pin preamplifier input socket fitted to the range of Brüel\&Kjær measuring amplifiers and frequency analyzers, to which the microphone assemblies can be connected directly. For operation with other equipment and for special applications, a microphone assembly can be powered by a Brüel\&Kjær power supply. These power supplies provide the necessary voltages to the cartridge and preamplifier via a 7-pin socket and pass the signal through without compromising noise or frequency response. Sound intensity probes are connected to ancillary equipment via 18-pin LEMO connectors. When the microphone cartridges are used together with a pre-amplifier, which will influence the response of the total assembly. The size of the influence depends on the preamplifier input impedance, the capacitance of the microphone (and adaptor), and the attenuation/ amplification of the preamplifier itself. The frecquecy responses are shown in Figures 4-7. Microphone specifications are found in Tables 1-2.

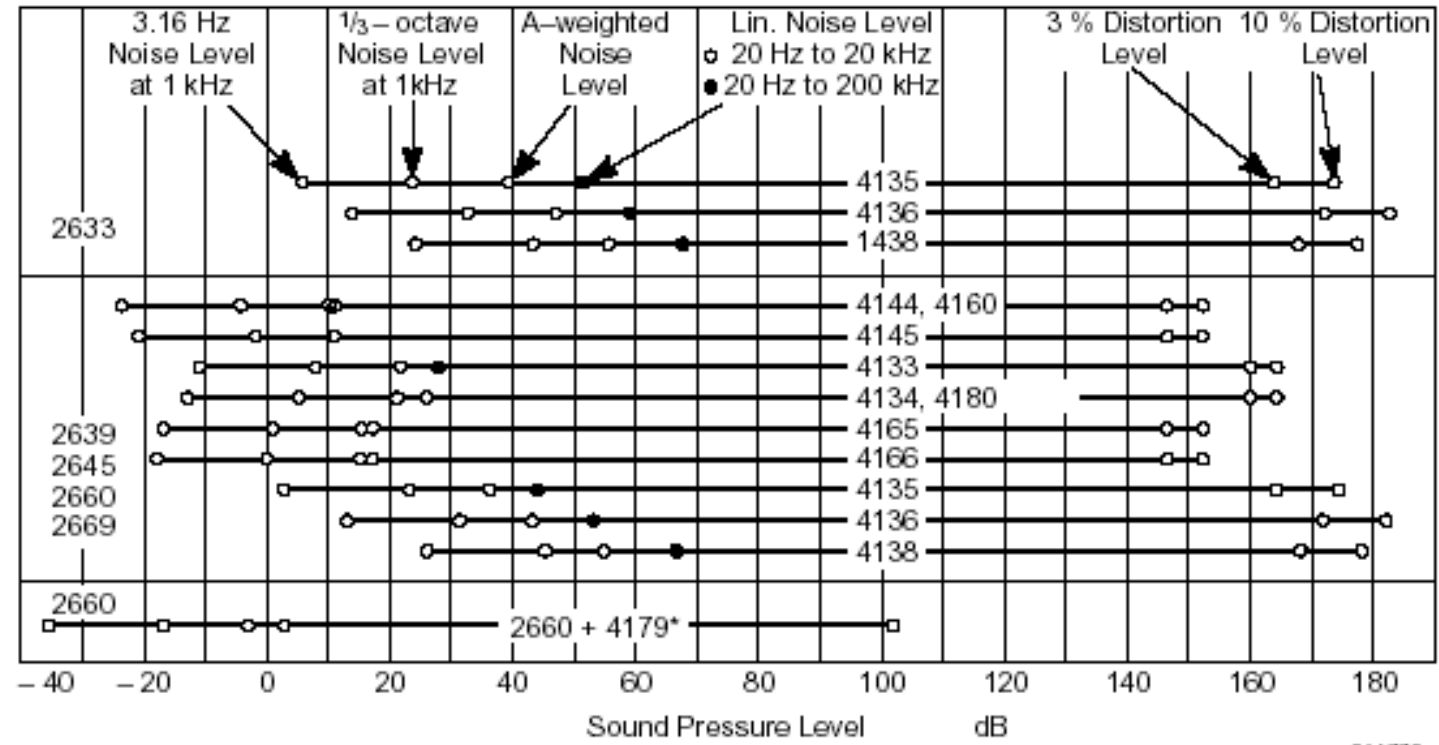

Figure 4- shows typical dynamic ranges of microphone and preamplifier assembly combinations (Brüel\&Kjær, 2002). 


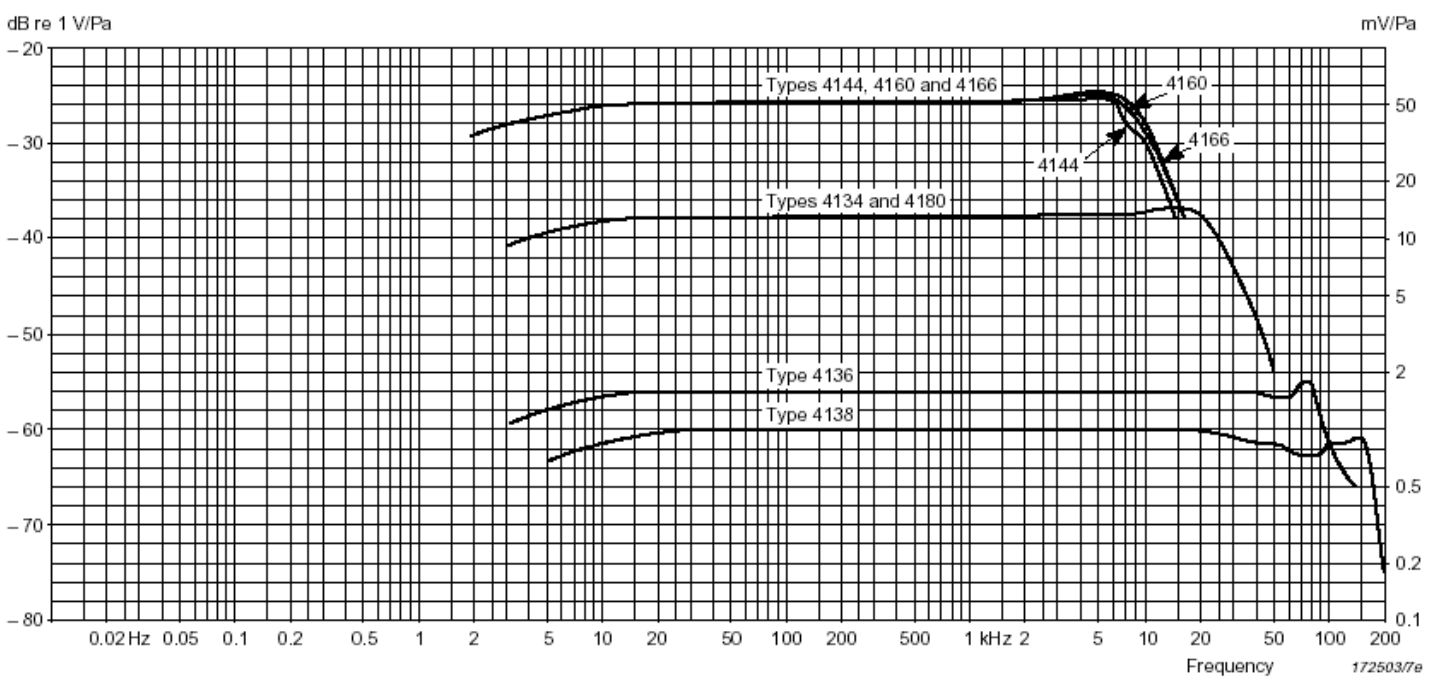

Figure 5- Typical frequency responses of the different pressure response microphones recorded by means of the electrostatic actuator method (Brüel\&Kjær, 2002).

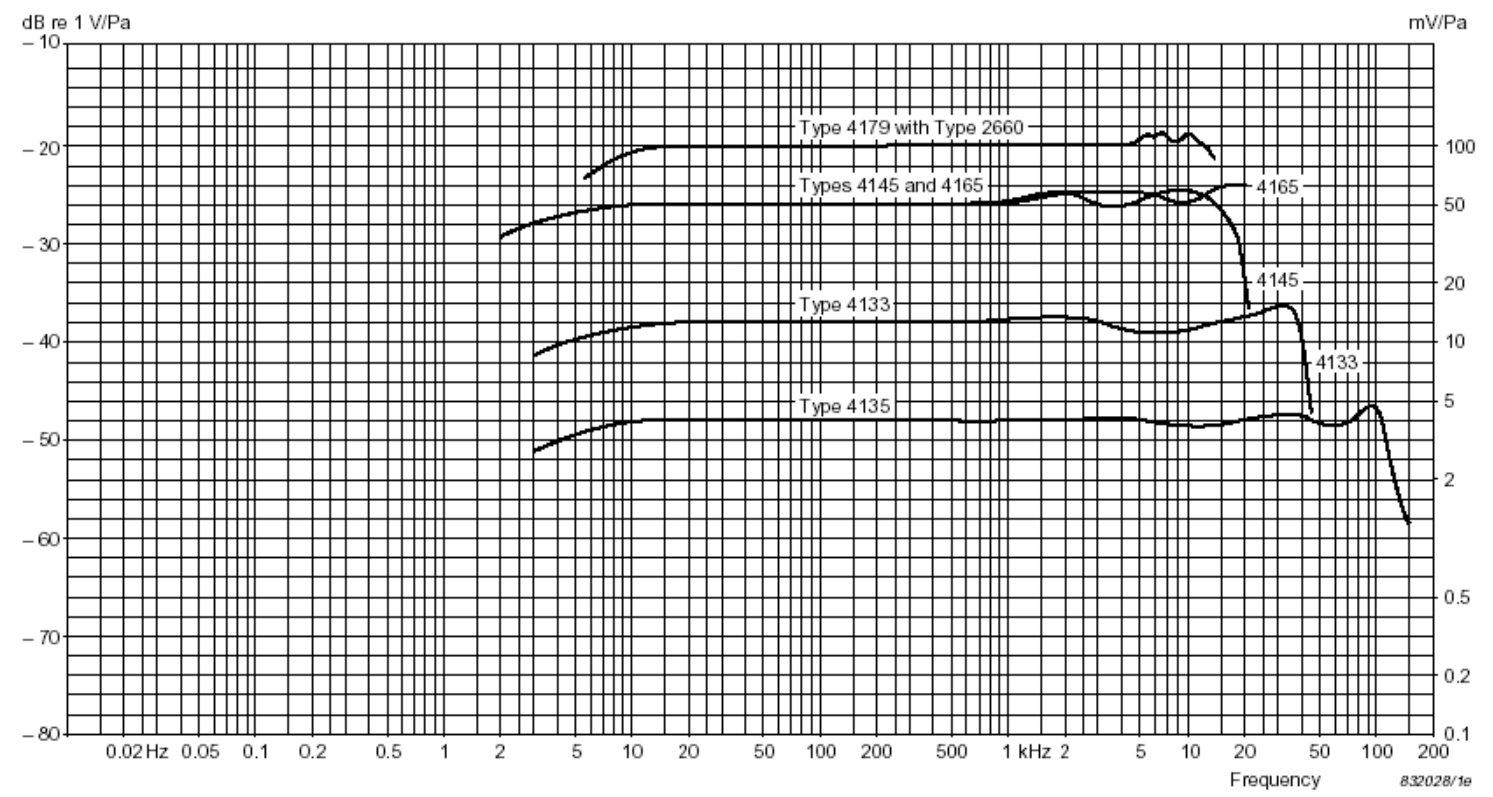

Figure 6- Typical $0^{\circ}$ incidence free-field frequency responses of the different free-field microphones recorded by means of the electrostatic-actuator method (Brüel\&Kjær, 2002). 


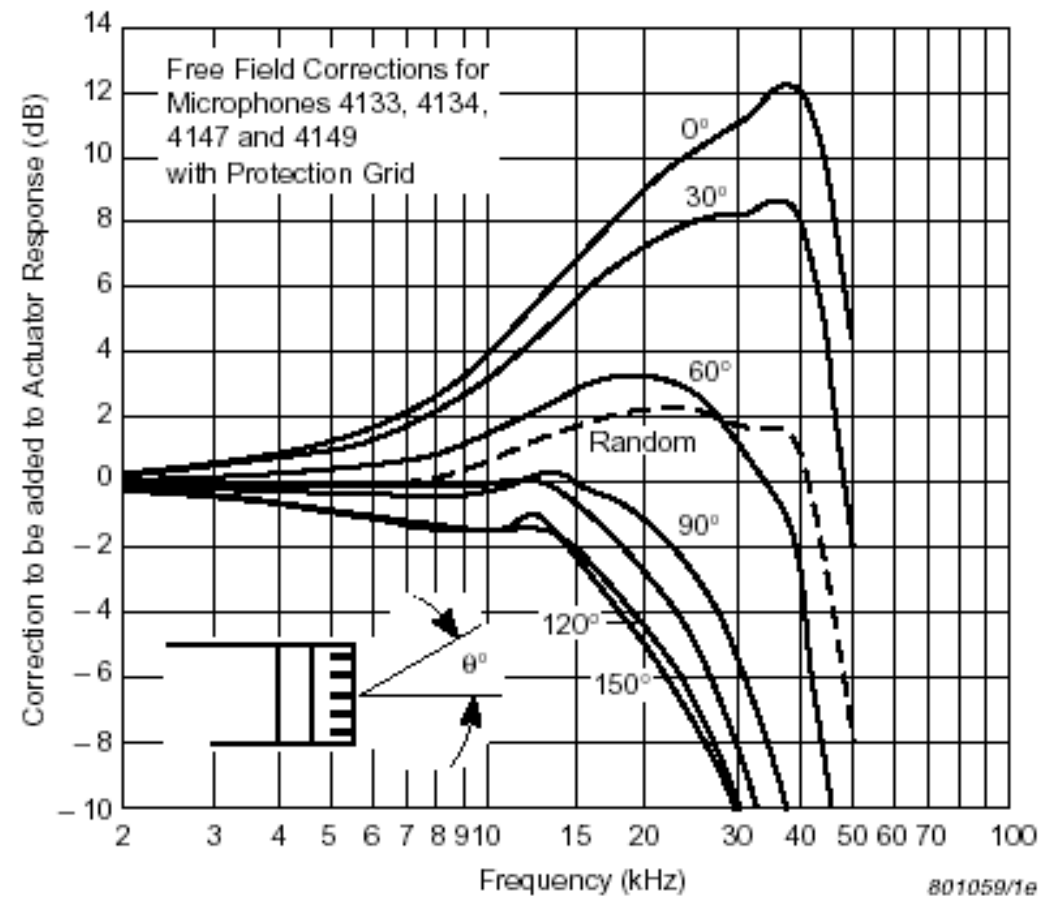

Figure 7 - Free field corrections for the B \& K model 4133 and 4134 microphones operating characteristics (Brüel\&Kjær, 2002).

\begin{tabular}{|c|c|c|}
\hline $\begin{array}{l}\text { The data below are valid at } 23^{\circ} \mathrm{C}, 101.3 \mathrm{kPa} \text { and } \\
50 \% \mathrm{RH} \text { unless otherwise specified }\end{array}$ & $\begin{array}{l}\text { DIAPHRAGM RESONANCE FREQUENCY: } \\
24 \mathrm{kHz}\left(90^{\circ} \text { phase-shift) }\right.\end{array}$ & $\begin{array}{l}\text { INFLUENCE OF HUMIDITY: } \\
<0.1 \mathrm{~dB} \text { in the absence of condensation }\end{array}$ \\
\hline TYPICAL USES: & POLARIZATION VOLTAGE: & DIMENSIONS: \\
\hline $\begin{array}{l}\text { General electroacoustic purposes, loudspeaker } \\
\text { and microphone measurements }\end{array}$ & External: $200 \mathrm{~V}$ & $\begin{array}{ll}\text { Diameter: } & 13.2 \mathrm{~mm}(0.52 \mathrm{in}) \text { (with grid) } \\
& 12.7 \mathrm{~mm}(0.50 \mathrm{in}) \text { (without grid) }\end{array}$ \\
\hline $\begin{array}{l}\text { NOMINAL DIAMETER: } \\
1 / 2^{\prime \prime}\end{array}$ & $\begin{array}{l}\text { POLARIZED CARTRIDGE CAPACITANCE*: } \\
18 \mathrm{pF} \text { at } 250 \mathrm{~Hz}\end{array}$ & $\begin{array}{ll}\text { Height: } & 12.6 \mathrm{~mm}(0.49 \mathrm{in}) \text { (with grid) } \\
& 11.7 \mathrm{~mm}(0.46 \mathrm{in}) \text { (without grid) } \\
\text { Thread for preamplifier mounting: } 11.7 \mathrm{~mm} \text { - }\end{array}$ \\
\hline $\begin{array}{l}\text { FREQUENCY RESPONSE } \\
\text { CHARACTERISTIC: }\end{array}$ & $\begin{array}{l}\text { MEAN TEMPERATURE COEFFICIENT: } \\
-0.002 \mathrm{~dB} /{ }^{\circ} \mathrm{C}\left(250 \mathrm{~Hz},-10^{\circ} \mathrm{C}<\mathrm{t}<+50^{\circ} \mathrm{C}\right)\end{array}$ & 60UNS \\
\hline Free-field, $0^{\circ}$ incidence & $\begin{array}{l}\text { EQUIVALENT AIR VOLUME: } \\
10 \mathrm{~mm}^{3}(250 \mathrm{~Hz})\end{array}$ & Ordering Information \\
\hline $\begin{array}{l}\text { OPEN CIRCUIT FREQUENCY RESPONSE }{ }^{\star} \text { : } \\
0^{\circ} \text { incidence free-field response: } \\
4 \mathrm{~Hz} \text { to } 40 \mathrm{kHz}: \pm 2 \mathrm{~dB}\end{array}$ & $\begin{array}{l}\text { EXPECTED LONG-TERM STABILITY: } \\
>1000 \text { years } / \mathrm{dB} \text { at } 20^{\circ} \mathrm{C}\end{array}$ & Type $4133 \quad 1 / 2^{\prime \prime}$ Microphone \\
\hline $\begin{array}{l}\text { In aocordance with IEC } 651 \text { Type 0, Type } 1 \text { and } \\
\text { ANSIS1.12, Type M }\end{array}$ & $\begin{array}{l}>2 \text { hours/dB at } 150^{\circ} \mathrm{C} \\
\text { INFLUENCE OF STATIC PRESSURE: }\end{array}$ & $\begin{array}{l}\text { Suitable Preamplifiers: } \\
\text { Type } 2639 \quad 1 / 2^{\circ} \text { Microphone Preamplifier } \\
\text { Type } 2645 \quad 1 / 2^{\circ} \text { Microphone Preamplifier }\end{array}$ \\
\hline $\begin{array}{l}\text { OPEN CIRCUIT SENSITIVITY }(1000 \mathrm{~Hz})^{*} \text { : } \\
-38 \mathrm{~dB} \text { re. } 1 \mathrm{~V} / \mathrm{Pa}, 12.5 \mathrm{mV} / \mathrm{Pa}\end{array}$ & $\begin{array}{l}-0.007 \mathrm{~dB} / \mathrm{kPa} \text {, typical } \\
\text { INFLUENCE OF VIBRATION: }\end{array}$ & $\begin{array}{ll}\text { Type } 2660 & 1 / 2^{\circ} \text { Low-level Microphone } \\
& \text { Preamplifier } \\
\text { Type 2669B } & 1 / 2^{\circ} \text { Microphone Preamplifier }\end{array}$ \\
\hline $\begin{array}{l}\text { LOWER LIMITING FREQUENCY }(-3 \mathrm{~dB}) \text { : } \\
1 \mathrm{~Hz} \text { to } 3 \mathrm{~Hz} \text { (vent exposed to sound) }\end{array}$ & INFLUENCE OF MAGNETIC FIELD: & $\begin{array}{l}\text { Type 2669L } 1 / 2 \text {. Microphone Preamplifier with } \\
\text { LEMO connector }\end{array}$ \\
\hline $\begin{array}{l}\text { CARTRIDGE THERMAL NOISE: } \\
20 \mathrm{~dB}(\mathrm{~A})\end{array}$ & $20 \mathrm{~dB}$ re. $20 \mu \mathrm{Pa}$ in $50 \mathrm{~Hz}, 80 \mathrm{~A} / \mathrm{m}$ field & $\begin{array}{l}\text { For information on microphone calibration } \\
\text { equipment and microphone acoessories, please } \\
\text { refer to the relevant product data sheets }\end{array}$ \\
\hline $\begin{array}{l}3 \% \text { DISTORTION LIMIT (UPPER): } \\
>160 \mathrm{~dB} \text { re. } 20 \mu \mathrm{Pa} \text { at } 100 \mathrm{~Hz}\end{array}$ & - Individually calibrated & \\
\hline
\end{tabular}

Table 1 - Brüel\&Kjær model 4133 condenser microphone specifications (Brüel\&Kjær, 2002). 


\begin{tabular}{|c|c|c|}
\hline $\begin{array}{l}\text { The data below are valid at } 23^{\circ} \mathrm{C}, 101.3 \mathrm{kPa} \text { and } \\
50 \% \mathrm{RH} \text { unless otherwise specified }\end{array}$ & $\begin{array}{l}\text { DIAPHRAGM RESONANCE FREQUENCY: } \\
23 \mathrm{kHz}\left(90^{\circ} \text { phase-shift) }\right.\end{array}$ & $\begin{array}{l}\text { INFLUENCE OF HUMIDITY: } \\
<0.1 \mathrm{~dB} \text { in the absence of condensation }\end{array}$ \\
\hline TYPICAL USES: & POLARIZATION VOLTAGE: & \multirow{4}{*}{ 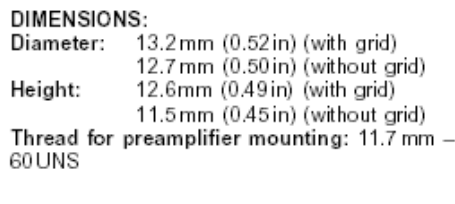 } \\
\hline $\begin{array}{l}\text { Medium- and high-level measurements in the } \\
\text { audio range and flush mounted measurements }\end{array}$ & External: $200 \mathrm{~V}$ & \\
\hline $\begin{array}{l}\text { of noise. Especially suitable where good ran- } \\
\text { dom-incidence characteristics are required }\end{array}$ & $\begin{array}{l}\text { POLARIZED CARTRIDGE CAPACITANCE: } \\
18.5 \mathrm{pF} \text { at } 250 \mathrm{~Hz}\end{array}$ & \\
\hline $\begin{array}{l}\text { NOMINAL DIAMETER: } \\
1 / 2^{5}\end{array}$ & $\begin{array}{l}\text { MEAN TEMPERATURE COEFFICIENT: } \\
-0.002 \mathrm{~dB} /{ }^{\circ} \mathrm{C} \quad\left(-10^{\circ} \mathrm{C}<\mathrm{t}<+50^{\circ} \mathrm{C}\right)\end{array}$ & \\
\hline $\begin{array}{l}\text { FREQUENCY RESPONSE } \\
\text { CHARACTERISTICS: } \\
\text { Random-Incidence and Pressure }\end{array}$ & $\begin{array}{l}\text { EQUIVALENT AIR VOLUME: } \\
10 \mathrm{~mm}^{3}(250 \mathrm{~Hz})\end{array}$ & Ordering Information \\
\hline OPEN CIRCUIT FREQUENCY RESPONSE*: & $\begin{array}{l}\text { EXPECTED LONG-TERM STABILITY: } \\
>1000 \text { years } / \mathrm{dB} \text { at } 20^{\circ} \mathrm{C}\end{array}$ & Type $4134 \quad 1 / 2^{\circ}$ Microphone \\
\hline $4 \mathrm{~Hz}$ to $20 \mathrm{kHz}: \pm 2 \mathrm{~dB}$ & INFLUENCE OF STATIC PRESSURE: & \multirow{2}{*}{ 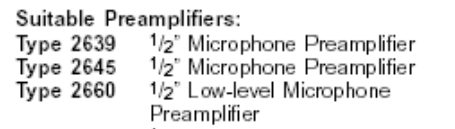 } \\
\hline $\begin{array}{l}\text { OPEN CIRCUIT SENSITIVITY }(250 \mathrm{~Hz})^{*} \text { : } \\
-38 \pm 1.5 \mathrm{~dB} \text { re. } 1 \mathrm{~V} / \mathrm{Pa}, 12.5 \mathrm{mV} / \mathrm{Pa}\end{array}$ & $\begin{array}{l}-0.007 \mathrm{~dB} / \mathrm{kPa} \text {, typical } \\
\text { INFLUENCE OF VIBRATION: }\end{array}$ & \\
\hline $\begin{array}{l}\text { LOWER LIMITING FREQUENCY }(-3 \mathrm{~dB}) \text { : } \\
1 \mathrm{~Hz} \text { to } 3 \mathrm{~Hz}\end{array}$ & $\begin{array}{l}67 \mathrm{~dB} \text { re. } 20 \mu \mathrm{Pa} \text { and } 1 \mathrm{~ms}^{-2} \text { axial vibration } \\
\text { INFLUENCE OF MAGNETIC FIELD: }\end{array}$ & $\begin{array}{ll}\text { Type 2669B } & 1 / 2^{2} \text { Microphone Preamplifier } \\
\text { Type } 2669 \mathrm{~L} & 1 / 2^{2} \text {. Microphone Preamplifier with } \\
& \text { LEMO connector }\end{array}$ \\
\hline $\begin{array}{l}\text { CARTRIDGE THERMAL NOISE: } \\
18 \mathrm{~dB}(\mathrm{~A})\end{array}$ & $20 \mathrm{~dB}$ re. $20 \mu \mathrm{Pa}$ in $50 \mathrm{~Hz}, 80 \mathrm{~A} / \mathrm{m}$ field & \multirow{2}{*}{$\begin{array}{l}\text { For information on microphone calibration } \\
\text { equipment and microphone acoessories, please } \\
\text { refer to the relevant product data sheets }\end{array}$} \\
\hline $\begin{array}{l}3 \% \text { DISTORTION LIMIT (UPPER): } \\
>160 \mathrm{~dB} \text { re. } 20 \mu \mathrm{Pa} \text { at } 100 \mathrm{~Hz}\end{array}$ & . Individually calibrated & \\
\hline
\end{tabular}

Table 2 - Brüel\&Kjær model 4134 condenser microphone specifications (Brüel\&Kjær, 2002).

\section{B. Data Acquisition}

The Omega DAQP-208 is a Type II PCMCIA data acquisition card with 4 differential or 8 single ended 12- bit A/D input channels (expandable to 128), with a maximum sampling rate of $100 \mathrm{kHz}$, and programmable gains of $1,2,4$, or 8 , which provide ranges of $\pm 1.25 \mathrm{~V}, \pm 2.5 \mathrm{~V}, \pm 5 \mathrm{~V}$, to $\pm 10 \mathrm{~V}$. A high gain option is also available providing gains of $1,10,100$ or 1000 , for ranges of $\pm 0.01 \mathrm{~V}, \pm 0.1 \mathrm{~V}, \pm 1 \mathrm{~V}$, to $\pm 10 \mathrm{~V}$ The DAQP-208 is also equipped with two 12-bit D/A output channels. The outputs can be updated individually when writing to the corresponding D/A port, or simultaneously when a synchronization signal comes. The DAQP-208 has a $2 \mathrm{~K}$ data FIFO which will significantly reduce CPU overhead, and a scan FIFO of 2048 entries, each of which can be specified with an input channel and its associated gain. It has a selectable scan speed of $10 \mathrm{~ms}$ to $40 \mathrm{~ms}$ per channel. Data acquisition may be initiated by a trigger signal or by using the DAQP-208's pre-trigger capability. The DAQP-208 has a 24-bit auto-reload pacer clock which generates accurate sampling rates from $0.006 \mathrm{~Hz}$ to $100 \mathrm{k} \mathrm{Hz}$ using an internal or external clock source. The pacer clock is actually a 24-bit auto-reload frequency divider. It contains a 24-bit divisor register, a 24-bit counter, and internal clock pre-scaler and a clock source multiplexer. The DAQP-208 also has a 16-bit timer/counter with an auto-reload and readout latch, which provides independent timing for the D/A channels, and operates with internal or external clock source and gate controls. The DAQP-208 is compatible with the Dasylab signal-processing package. Signal Conditioning/Expansion is possible through the SignalPro line of signal conditioners. These signal conditioners allow the DAQP-208 to read most process sensors and provides channel expansion up to 256 inputs. Drivers are also included for numerous third-party software packages including Labtech Notebook, DasyLab support, LabVIEW, and SnapMaster. 
Resolution: 12-Bit

Number of Channels:

4 differential / 8 single-ended, expandable to 128 with QTC

SignalPro Series (Section $\mathrm{H}$ )

Input Range: $\pm 10, \pm 5, \pm 2.5, \pm 1.25$

volts for DAQP-208 and $\pm 0.01 \mathrm{~V}$,

$\pm 0.1 \mathrm{~V}, \pm 1 \mathrm{~V}, \pm 10 \mathrm{~V}$ for DAQP-208H

Max Overvoltage: \pm 30 volts

Input Impedance: 10 M

Programmable Gains:

1,2,4,8 (DAQP-208)

1, 10, 100, 1000 (DAQP-208H)

Data FIFO: $2 \mathrm{~K}$

Scan FIFO: 2048 entries

Sampling Rate: $0.006 \mathrm{~Hz}$ to $100 \mathrm{kHz}$

(with internal clock)

Trigger Source: internal (software)

or external (TTL, analog)

Trigger Mode: continuous/ one-shot

Pre-trigger Capacity:

programmable, up to the data

FIFO depth

TTL Trigger: $0.8 \mathrm{~V}$ (low)/2.2 V(high), rising/falling edges

Analog Trigger: threshold set in full

$\mathrm{A} / \mathrm{D}$ input range $(+10 \mathrm{~V})$

rising/falling directions, $10 \mathrm{mV}$

hysteresis

Table 3 - DAQP-208H Specifications
External Clock Rate: DC-5MHz

Integral Linearity Error: +3 LSB

Differential Linearity Error:

$+3 /-2$ LSB

Full Scale Error: $+0.5 \%$

Aperture Delay: $40 \mathrm{~ns}$

ANALOG OUTPUT

Resolution: 12 -bit

Number of Channels: 2 single ended

Output Range: \pm 5 volts (bipolar)

Maximum Update Rate: $100 \mathrm{kHz}$

(10ms)

DC Output Impedance: $0 . \tilde{5}$

(typical)

Output Current: $\pm 2 \mathrm{~mA}$

Relative Accuracy: +1 LSB max

Bipolar Zero Error: +7 LSB max

Differential Nonlinearity:

+1 LSB max

Full Scale Error: +7 LSB max

COUNTER/TIMER

Word Length: 16-Bit, auto-reload

and read latch

Clock Source: internal (1 MHz)/

external (DC-5 MHz)

External Clock Input: TTL, pulse

width $>100 \mathrm{~ns}$, frequency $<5 \mathrm{MHz}$

\section{Signal Processing}

The data that has been collected from the series of mounted sensors will need to be processed in order to perform any analysis such as energy content, location of a noise source or frequency content. In order to carry out these analyses WVU has purchased the DASYLab version 7.0 signal-processing package.

DASYLab can conduct a variety of frequency analysis functions. The most important frequency analysis techniques are Octave analysis and the Fast Fourier Transform (FFT).

The Octave-Analysis module analyzes incoming signals with digital filters, optimized to a $40 \mathrm{KHz}$ sampling rate. Octave Analysis is the most basic measurement any sound measurement is an overall $\mathrm{dB}$ level. This is a single number, which represents the sound energy over the entire frequency range of the meter. It provides no information about the frequency content of the sound. We can obtain information on the frequency content by using filters. The most common are octave band and 1/3 octave band filters. Most of the frequency detail is provided by FFT analysis. 
The octave band measures the total acoustical energy within the pass-band of a band pass filter. The term "octave" denotes a doubling in frequency. Hence, each octave band covers a frequency range of one octave. We refer to the octave band by its center frequency. The center frequencies of successive filters are separated by one octave. The preferred octave band center frequencies (by international standard) are: 31.5, 63, 125, $250,500,1000,2000,4000,8000$ and $16000 \mathrm{~Hz}$. The shape of a typical octave filter is shown in Figure 7.4 below. The bandwidth of a filter is the width in frequency between the $-3 \mathrm{~dB}$ points. This is an example of a constant percentage bandwidth filter. The width of octave filters progressively increases with frequency. When plotted on a log scale, the shape of the band response is independent of frequency. The output of a percentage bandwidth filter is: $\mathrm{dB} /$ Bandwidth

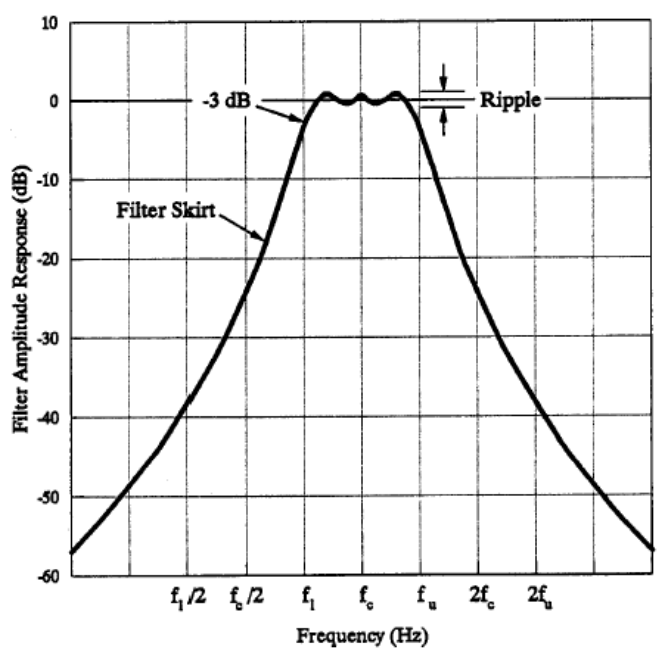

Figure 8 - Characteristics of an octave band filter (Lamancusa, 2000)

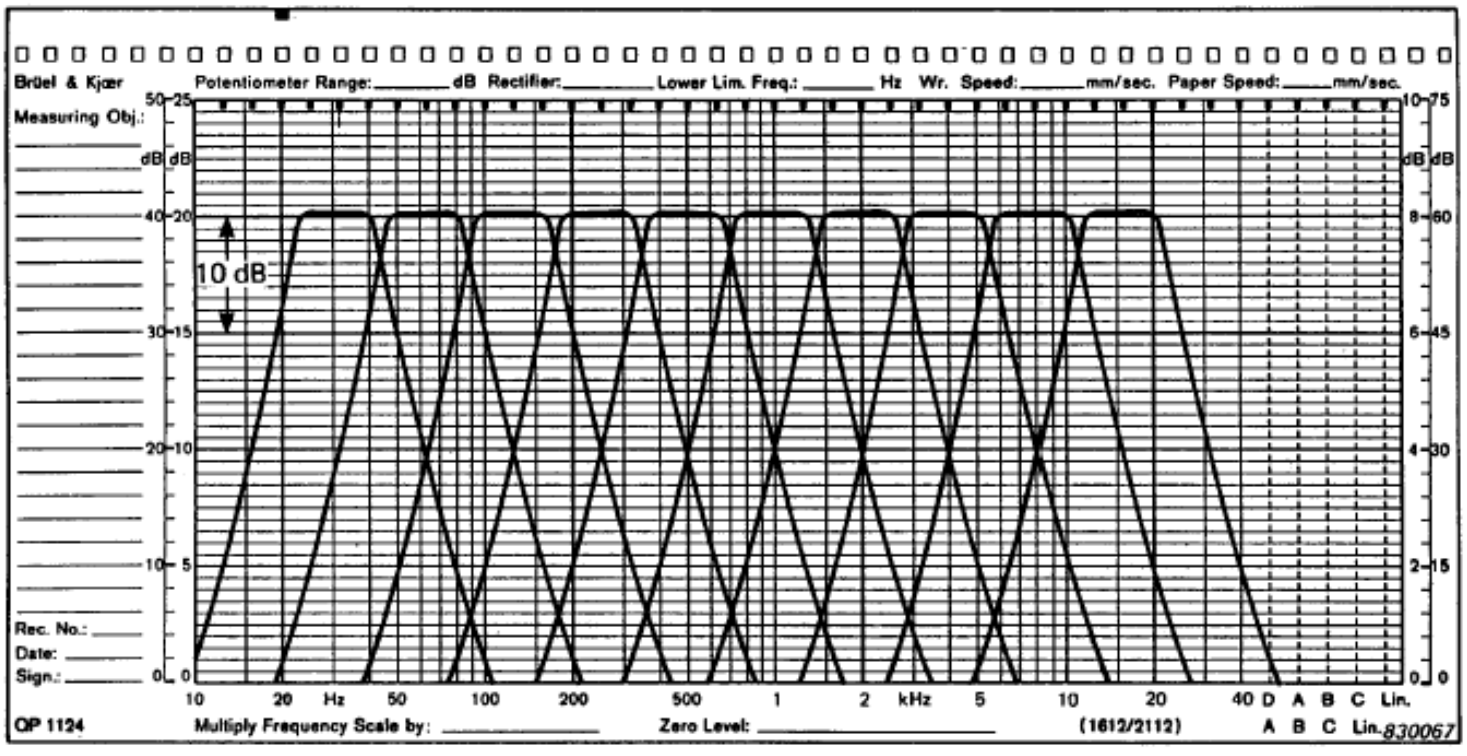

Figure 9 - Complete filter characteristics for a typical octave band filter set (Lamancusa, 2000) 


1/1 Octave Filter Relationships:
$f_{l}=2^{-1 / 2 f_{c}} \quad f_{u}=2^{1 / 2 f_{c}}$
$f_{c_{s+1}}=2 f_{c_{s}}=$ center frequencies of adjacent filters
$f_{l}=$ lower cutoff frequency (to $-3 \mathrm{~dB}$ point), $\mathrm{Hz}$
$f_{u}=$ upper cutoff frequency (to $-3 \mathrm{~dB}$ point), $\mathrm{Hz}$

The one-third, one-tenth octave analysis provide more detail is sometimes needed to obtain adequate frequency resolution, hence the need for bandwidths finer than one octave. The choice of filter bandwidth depends on the nature of the measured noise - is it broadband or does it have significant pure tones which you want to identify? Closely spaced pure tones will not be discovered by a wide bandwidth analysis (Lamancusa, 2000).

$$
\begin{gathered}
\text { 1/3 Octave Filter Relationships: } \\
f_{l}=2^{-1 / 6 f_{c}} \quad f_{u}=2^{1 / 6 f_{c}} \\
f_{c_{i+1}}=2^{1 / 3} f_{c_{i}}=1.26 f_{c_{s}}=\text { center frequencies of adjacent filters }
\end{gathered}
$$

1/10 octave - Each full octave is spanned by ten $1 / 10$ octave bands (not very common anymore, due to the widespread availability of inexpensive FFT analyzers), (Lamancusa, 2000)

$$
\begin{aligned}
& \text { General 1/n Octave Filter Relationships: } \\
& \qquad f_{l}=2^{-(1 / 2 n) f_{c}} \quad f_{u}=2^{(1 / 2 n) f_{c}} \\
& f_{c_{i+1}}=2^{1 / n} f_{c_{s}}
\end{aligned}
$$

\section{General 1/n Octave Filter Relationships:}

The center frequencies and upper and lower limits of the octave and $1 / 3$ octave filter bands are shown in Table 1 below (Lamancusa, 2000). 


\begin{tabular}{|c|c|c|c|c|c|}
\hline \multicolumn{3}{|c|}{ Octave } & \multicolumn{3}{|c|}{ 1/3 Octave } \\
\hline Lower limit & Center Freq & Upper limit & Lower limit & Center Freq & Upper limit \\
\hline \multirow[t]{3}{*}{$11 \mathrm{~Hz}$} & $16 \mathrm{~Hz}$ & $22 \mathrm{~Hz}$ & $14.1 \mathrm{~Hz}$ & $16 \mathrm{~Hz}$ & $17.8 \mathrm{~Hz}$ \\
\hline & & & 17.8 & 20 & 22.4 \\
\hline & & & 22.4 & 25 & 28.2 \\
\hline \multirow[t]{3}{*}{22} & 31.5 & 44 & 28.2 & 31.5 & 35.5 \\
\hline & & & 35.5 & 40 & 44.7 \\
\hline & & & 44.7 & 50 & 56.2 \\
\hline \multirow[t]{3}{*}{44} & 63 & 88 & 56.2 & 63 & 70.8 \\
\hline & & & 70.8 & 80 & 89.1 \\
\hline & & & 89.1 & 100 & 112 \\
\hline \multirow[t]{3}{*}{88} & 125 & 177 & 112 & 125 & 141 \\
\hline & & & 141 & 160 & 178 \\
\hline & & & 178 & 200 & 224 \\
\hline \multirow[t]{3}{*}{177} & 250 & 355 & 224 & 250 & 282 \\
\hline & & & 282 & 315 & 355 \\
\hline & & & 355 & 400 & 447 \\
\hline \multirow[t]{3}{*}{355} & 500 & 710 & 447 & 500 & 562 \\
\hline & & & 562 & 630 & 708 \\
\hline & & & 708 & 800 & 891 \\
\hline \multirow[t]{3}{*}{710} & 1000 & 1420 & 891 & 1000 & 1122 \\
\hline & & & 1122 & 1250 & 1413 \\
\hline & & & 1413 & 1600 & 1778 \\
\hline \multirow[t]{3}{*}{1420} & 2000 & 2840 & 1778 & 2000 & 2239 \\
\hline & & & 2239 & 2500 & 2818 \\
\hline & & & 2818 & 3150 & 3548 \\
\hline \multirow[t]{3}{*}{2840} & 4000 & 5680 & 3548 & 4000 & 4467 \\
\hline & & & 4467 & 5000 & 5623 \\
\hline & & & 5623 & 6300 & 7079 \\
\hline \multirow[t]{3}{*}{5680} & 8000 & 11360 & 7079 & 8000 & 8913 \\
\hline & & & 8913 & 10000 & 11220 \\
\hline & & & 11220 & 12500 & 14130 \\
\hline \multirow[t]{2}{*}{11360} & 16000 & 22720 & 14130 & 16000 & 17780 \\
\hline & & & 17780 & 20000 & 22390 \\
\hline
\end{tabular}

Table 4 - Center and cutoff frequencies (Hz) for standard full octave and $1 / 3$ octave filters (Lamancusa, 2000)

Fast Fourier Transform, is a narrow band, constant bandwidth analysis (the frequency resolution does not change over the frequency range) FFT refers to the numerical algorithm used to calculate the Fourier transform in "real time" (in less time than it takes to acquire the actual data). In layperson's terms, the FFT determines the frequency content of a time signal. The mathematical definition of a Fourier transform is:

$$
X(f)=\int_{-\infty}^{+\infty} x(t) e^{-j 2 \pi f t} d t
$$

The FFT algorithm discretizes this calculation. It requires a finite number of time data points, typically a power of 2 , such as 512 (29) or 1024. It is a transformation from time 
to frequency (Lamancusa, 2000).

DASYLab also has a number of other processing functions and modules to perform various data analysis tasks and they are as follows:

- Transfer Function module and the Weighting module to freely weight spectra

- Convolution module with preset filter vectors. Coherence analysis, automatic average and weighting of transfer functions, as well as automatic acceptance values provide convenient handling for needed computation.

- Universal Filter Module offers user defined digital FIR and IRR Filter.

This software also supports the creation of FIR filters.

- Classification options are implemented in the Rainflow and the 2-Channel Classification module as a part of the Analysis Add-on. They contain all-important methods to analyze Time-Stress functions. In addition to the most modern method, the Rainflow classification, reflected by the module's name, other parametric methods based on DIN 45667 are available. The 2-channel classification allows the linking of two timestress functions to analyze load-bearing collectives. Up to 256 classes, settable hysteresis, conditions and the option to analyze apparent residues offer a wide range of methods making this module a useful instrument for signal analysis.

- Polar/Cartesian conversion function converts data values between polar and Cartesian Coordinates.

- Harmonic Distortion function calculates the amplitude and phase of the fundamental frequency and up to 48 harmonic waves.

- Period Check function calculates the period of a signal by checking its zero crossings (DASYLab, 2002). 


\section{Results and Discussion}

Pipeline monitors will only have access to the natural gas inside the pipeline via a 0.5 inch pipe tap, monitoring changes in flow rate and temperature are out of the question. This leaves monitoring the acoustic pressure step or ramp functions and acoustic spectra in the low frequency range. The technology for zero frequency pressure step or ramp function monitoring is not highly developed, as needed to achieve a high signal to noise ratio over a wide range of DB or acoustic pressure levels. Commercial instrumentation based on piezoelectric, accelerometers or bellows concentrate on providing linearity between input signal strength and output recorded signal. As DB $=20 \log \left(\mathrm{p} / \mathrm{p}_{\mathrm{ref}}\right)$, such a sensor with accuracy as low as $0.1 \%=10^{-3}$ of full-scale range, will not be able to detect anything over more than a three fold DB range! (a 1 to $3 \mathrm{DB}$ range, for example from 40 to $120 \mathrm{DB}$ represents a pressure ratio $\mathrm{p} / \mathrm{p}_{\mathrm{ref}}=10^{-3}$ ). This is the reason why WVU is working on the development of novel and nonlinear sensors, capable of at least a ten to hundred fold improvement in accuracy of full-scale range. Keeping in mind, it must also be able to operate at pressures up to 1000 psi and not change in calibration upon rapid pressure changes, which eliminates the use of bellows for sensors.

The research at WVU is currently concentrating on developing acoustic ramp-signal sensors with aerodynamic signal amplification. The advantage of aerodynamic signal amplification is that it does not amplify random pipeline noise but only the ramp-signal itself.

One solution found is the use of a rigid container connected to the pipeline by three items: a small needle valve and in parallel with it two small spring loaded check valves mounted for flow in opposite directions. They limit the pressure difference between the container and the pipeline to their set value, for example $\pm 1 \mathrm{psi}$. The passage of any ramp function inside the pipeline will produce a proportional pressure differential between the container and the pipeline, which can safely be measured by a \pm 1 psi differential pressure commercial available transducer. This allows detecting pipeline pressure transients down to 10 Pascal per second!

Another solution under development uses the sensor housing itself as the rigid container above and replaces the commercial available differential pressure transducer mentioned above with a new aerodynamic signal amplifier now under development. It utilizes the same diaphragm principle as a high quality capacitance type microphone. However the microphone uses acoustic pressure to deflect a diaphragm. Its change in capacitance is measured with an oscillator circuit. The microphone is limited to detecting signals at frequencies above $1 / 4$ Hertz. The new aerodynamic signal amplifier is a large diaphragm held in close proximity to a rigid brass plate with a $1 / 2$ " NPT hole in the middle. Gas from the sensor housing enters at the diaphragm perimeter $\left(\mathrm{r}_{\mathrm{i}}\right)$ at velocity $\left(\mathrm{V}_{\mathrm{i}}\right)$ and flows in a sink-flow type fashion to the exit hole in the center starting at radius $\left(\mathrm{r}_{\mathrm{e}}\right)$ and from there through the $1 / 2$ " pipe nipple to the pipeline. Such sink-flow between two closely spaced discs creates a pressure differential $(\Delta \mathrm{p})$ on the diaphragm which is far greater then the dynamic pressure of the flow exiting through the $1 / 2$ " pipe nipple. The value of $(\Delta p)$ starts at $\left(r_{i}\right)$ with $\left(1 / 2 \rho V_{i}^{2}\right)$ and increases to a maximum value of $\left(r_{i} / r_{e}\right)^{2} *\left(1 / 2 \rho V_{i}^{2}\right)$ at the exit and 
tapers of to zero on the centerline where $V=0$. For a constant spacing (s) this pressure force integrates to:

$$
F_{D}=\frac{1}{2} \rho V_{i}^{2} 2 \pi \int_{r_{e}}^{r_{i}}\left(\frac{r_{i}}{r}\right)^{2} r d r+\frac{1}{2} \rho V_{i}^{2} 2 \pi\left(\frac{r_{i}}{r_{e}}\right)^{2} \int_{0}^{r_{e}}\left(\frac{r}{r_{e}}\right) r d r=\rho V_{i}^{2} \pi r_{i}^{2}\left[\ln \frac{r_{i}}{r_{e}}+\frac{1}{3}\right]
$$

Divide this diaphragm force by the momentum force in the exit flow through the $1 / 2$ " nipple radius $\left(\mathrm{r}_{\mathrm{o}}\right.$ ) which is $F_{o}=\rho V_{o}^{2} \pi r_{o}^{2}$ and relate velocities $\mathrm{V}_{\mathrm{i}}$ to $\mathrm{V}_{\mathrm{o}}$ by the spacing (s) gives: $\mathrm{V}_{\mathrm{i}}=\mathrm{V}_{\mathrm{o}} * \mathrm{r}_{\mathrm{o}}{ }^{2} /\left(2 \mathrm{r}_{\mathrm{i}}{ }^{*} \mathrm{~s}\right)$, provided the aerodynamic force augmentation $\alpha=F_{D} / F_{o}$

$$
\alpha=\left(\frac{r_{o}^{2}}{4 s^{2}}\right)\left[\ln \frac{r_{i}}{r_{e}}+\frac{1}{3}\right]
$$

Using: $\mathrm{r}_{\mathrm{i}}=39 \mathrm{~mm}, \mathrm{r}_{\mathrm{e}}=10 \mathrm{~mm}$ and $\mathrm{r}_{\mathrm{o}}=6.5 \mathrm{~mm}$, find:

$\alpha=18$ for $\mathrm{s}=1 \mathrm{~mm}$ and $\alpha=61$ for $\mathrm{s}=0.542 \mathrm{~mm}$ where $\mathrm{V}_{\mathrm{i}}=\mathrm{V}_{\mathrm{o}}$.

To measure very small forces, one has to float the diaphragm on peripheral supports, to the specified spacing. This free floating allows it to deflect into a spherical shape.

Machining a slightly convex profile in the rigid brass plate and slightly pre-loading the diaphragm from the center improves its stability and signal linearity. Although a straingage beam could be used the measure the diaphragm deflection, its change in capacitance provides a more sensitive signal.

The velocity $\mathrm{V}_{\mathrm{o}}$ induced in the $1 / 2$ " pipe nipple by a leak induced pressure transient is very small and depends on its area $A_{o}$ which for a schedule 40 nipple with $r_{o}=0.311 "$ gives area $A_{o}=0.2 * 10^{-3} \mathrm{~m}^{2} . V_{o}$ is directly proportional to the volume of the sensor holding housing. This volume has been estimated to be: $\mathrm{Vol}=0.8$ liter $=0.8^{*} 10^{-3} \mathrm{~m}^{3}$. Differentiating the equation of state, and assuming isothermal expansion, gives:

$$
\frac{d p}{d t}=\frac{d m}{d t}\left(\frac{R^{*} T}{V o l}\right)=-\rho V_{o} A_{o}\left(\frac{R^{*} T}{V o l}\right)=-V_{o} p\left(\frac{A_{o}}{V o l}\right)
$$

For performance calibration on the WVU blow down wind tunnel with air at a typical pressure $\mathrm{p}=1 \mathrm{MPa}$ and $\mathrm{T}=300{ }^{\circ} \mathrm{K}$ find

$$
V_{o}(m / s)=-\frac{d p}{d t} \frac{V o l}{p A_{0}}=4.0 \times 10^{-6}-\frac{d p}{d t}
$$

For a ramp signal $\mathrm{dp} / \mathrm{dt}=-1 \mathrm{psi} / \mathrm{s}$ find $\mathrm{V}_{\mathrm{o}}=0.027 \mathrm{~m} / \mathrm{s}$ and $\mathrm{F}_{\mathrm{o}}=1.72 * 10^{-6}$ Newton. This indicates the importance of aerodynamic signal amplification for leak detection.

The diaphragm supported at its perimeter under load $\mathrm{F}_{\mathrm{D}}$ has a uniform stress and takes on a spherical shape of radius $\mathrm{R}$. The deflection angle (theta) at the perimeter is related to its radius of curvature by: $\sin ($ theta $)=r_{i} / R$. The perpendicular component of the tensile stress (sigma) at the perimeter equals the net load $\mathrm{F}_{\mathrm{D}}$. If the diaphragm thickness is $(\mathrm{t})$ then: sigma $=\mathrm{F}_{\mathrm{D}} /\left\{2 * \pi * \mathrm{r}_{\mathrm{i}} * \mathrm{t}^{*} \sin (\right.$ theta $\left.)\right\}$. The strain $\varepsilon$ is due to the difference between the inner and outer arc length or $\varepsilon=(\mathrm{R}-(\mathrm{R}-0.5 \mathrm{t})) / \mathrm{R}=0.5 \mathrm{t} / \mathrm{R}=\operatorname{sigma} / \mathrm{E}$, where $\mathrm{E}$ is the modulus of elasticity. Eliminate sigma in these two equations and solve for the radius of curvature $\mathrm{R}: \mathrm{R}=\mathrm{t} * \mathrm{r}_{\mathrm{i}} * \mathrm{SQRT}\left\{\mathrm{E}^{*} \pi / \mathrm{F}_{\mathrm{D}}\right\}$ 
The diaphragm centerline deflection:

$\operatorname{def}=R^{*}(1-\cos ($ theta $))=R^{*}\left(1-\operatorname{SQRT}\left(1-\sin ^{2}(\right.\right.$ theta $\left.)\right)=R^{*}\left(1-\operatorname{SQRT}\left(1-\left(\mathrm{r}_{\mathrm{i}} / \mathrm{R}\right)^{2}\right)\right.$

$\operatorname{def}=\mathrm{t}^{*} \mathrm{r}_{i} * \mathrm{SQRT}\left\{\mathrm{E}^{*} \pi / \mathrm{F}_{\mathrm{D}}\right\} *\left[1-\mathrm{SQRT}\left(1-1 /\left(\mathrm{t}^{2}\left\{\mathrm{E}^{*} \pi / \mathrm{F}_{\mathrm{D}}\right\}\right)\right)\right.$

For phosphor bronze diaphragm of thickness $t=0.005^{\prime \prime}=0.000127 \mathrm{~m}, \mathrm{E}=100 \mathrm{GPa}$ find deflection (def) for a force $\mathrm{F}_{\mathrm{D}}=1$ Newton: $\operatorname{def}=0.28 * 10^{-3} \mathrm{~m}=0.28 \mathrm{~mm}$

Additional computed characteristics of this diaphragm for operation during instrument calibration using compressed air are shown graphically in the Appendix 1.

\section{Conclusions}

Stationary detectors have been very successful inside power plants where the monitoring distances are relatively short. At distances up to $60 \mathrm{~km}$ away, only a few investigators acknowledge reliable leak detection. The main problem is caused by signal dissipation with distance, which increases almost linearly with frequencies above $1000 \mathrm{~Hz}$. As signal strength dissipates, the signal to noise ratio diminishes. These investigators attribute their successes to signal processing and relying on more than one type of signal to filter out false alarms. The five signals most frequently relied upon are: time rate of change in flow rate, temperature, pressure step or ramp functions and acoustic frequency/amplitude characteristics.

One solution being tested is the use of a rigid container connected to the pipeline by three items: a small needle valve and in parallel with it two small spring loaded check valves mounted for flow in opposite directions. They limit the pressure difference between the container and the pipeline to their set value, for example \pm 1 psi. The passage of any ramp function inside the pipeline will produce a proportional pressure differential between the container and the pipeline, which can safely be measured by a \pm 1 psi differential pressure commercial available transducer. This allows detecting pipeline pressure transients down to 10 Pascal per second!

Another solution under development uses the sensor housing itself as the rigid container above and replaces the commercial available differential pressure transducer mentioned above with a new aerodynamic signal amplifier now under development. It utilizes the same diaphragm principle as a high quality capacitance type microphone. However the microphone uses acoustic pressure to deflect a diaphragm. Its change in capacitance is measured with an oscillator circuit. The microphone is limited to detecting signals at frequencies above $1 / 4$ Hertz. Measure of the diaphragm deflection as a change in capacitance provides a more sensitive signal. 


\section{References:}

Brüel\&Kjær Condenser Microphone Cartridges - Types 4133 to 4181 product data sheets, document number BP 0100-17, http://www.bksv.com/pdf/Bp0100.pdf.

DASYLab 7.0 Data Acquisition System Laboratory Advertisement, 2002, DASYTEC USA, http://www.dasylab.net.

DAQP-208 Type II PCMCIA data acquisition card, product data sheets, D1-31 and D132, Omega scientific instruments, 2002 http://www.omega.com/DAS/pdf/DAQP-208.pdf.

Lamancusa, J.S., 12/4/2000, “Instrumentation for Noise Measurement”, Pennsylvania State University, http://www.me.psu.edu/lamancusa/me458/7_Instruments.pdf. 


\section{Appendix 1 - Diaphragm operating characteristics}

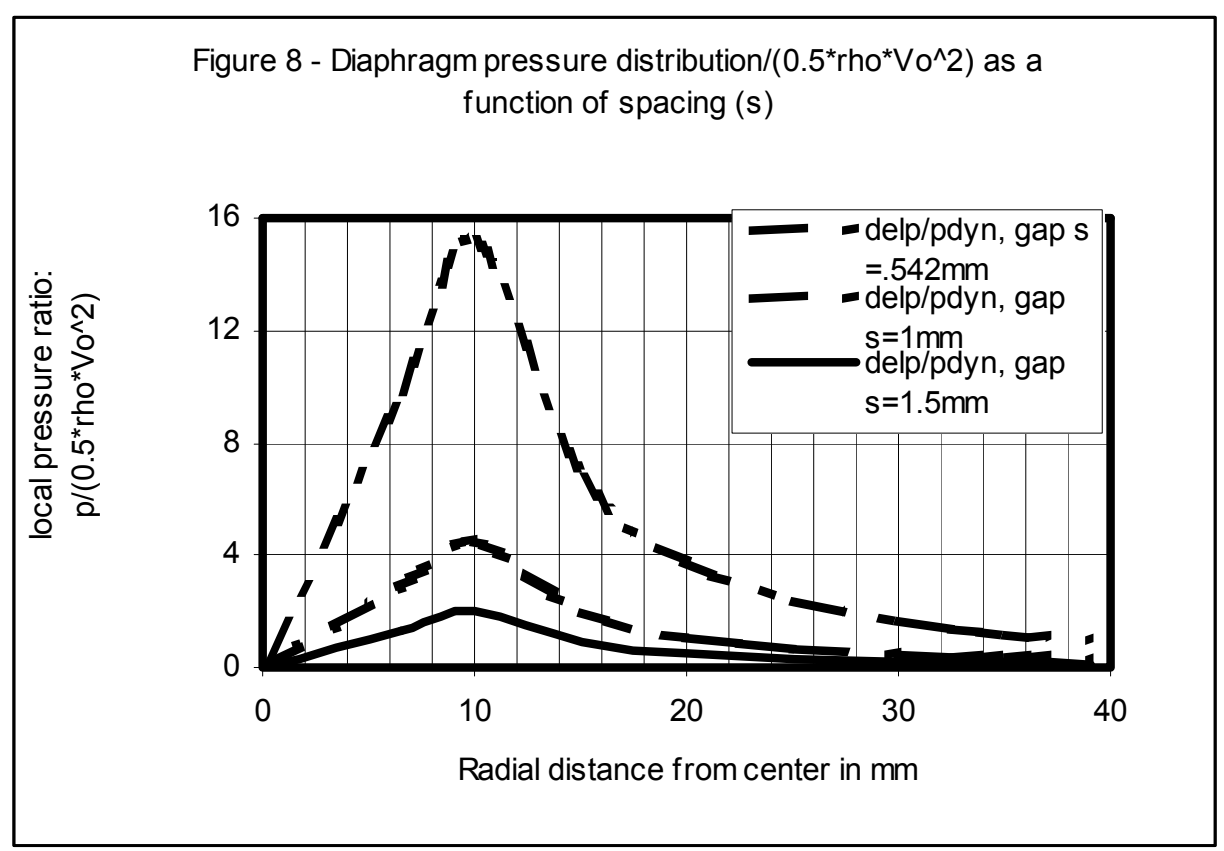

Figure 10 - Non-dimensional diaphragm pressure distributions

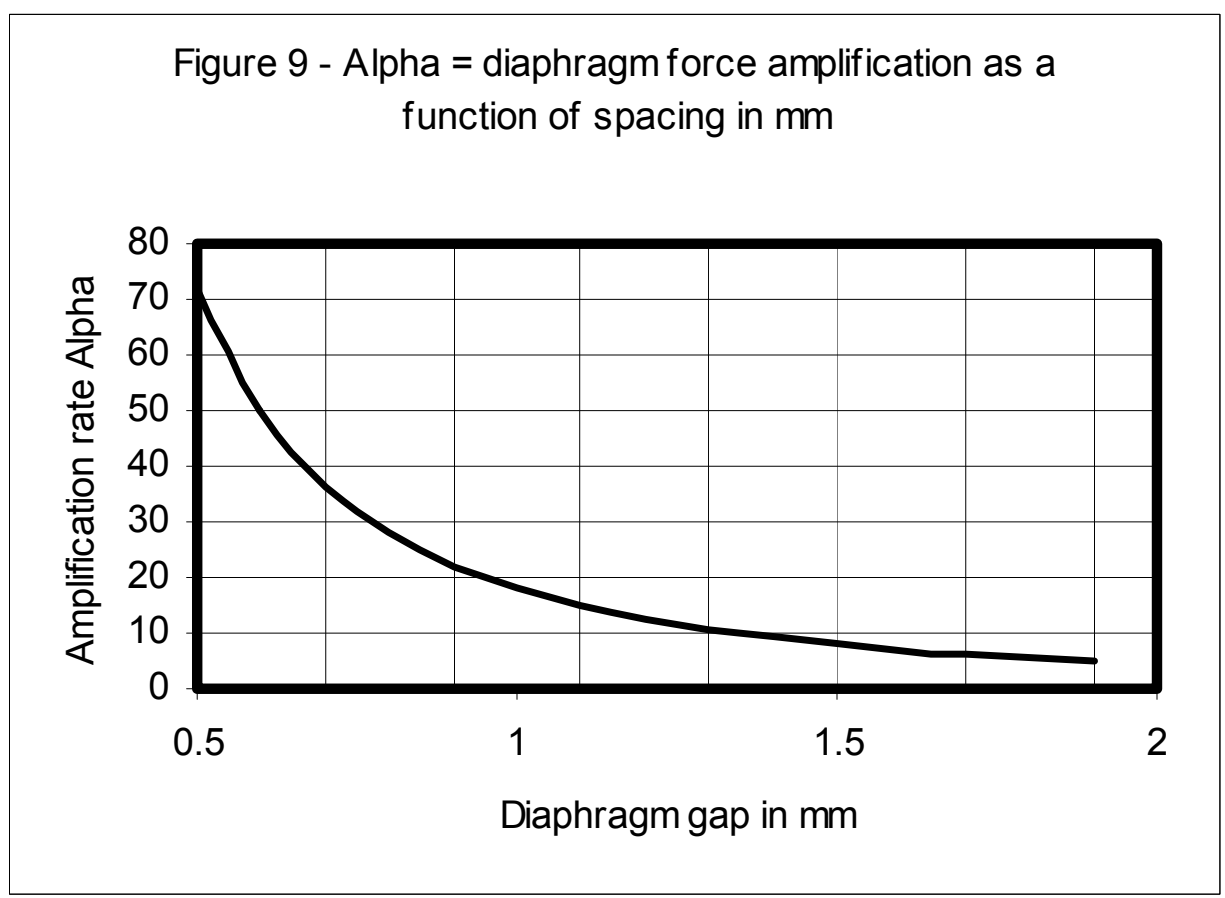

Figure 11 - Diaphragm force amplification 


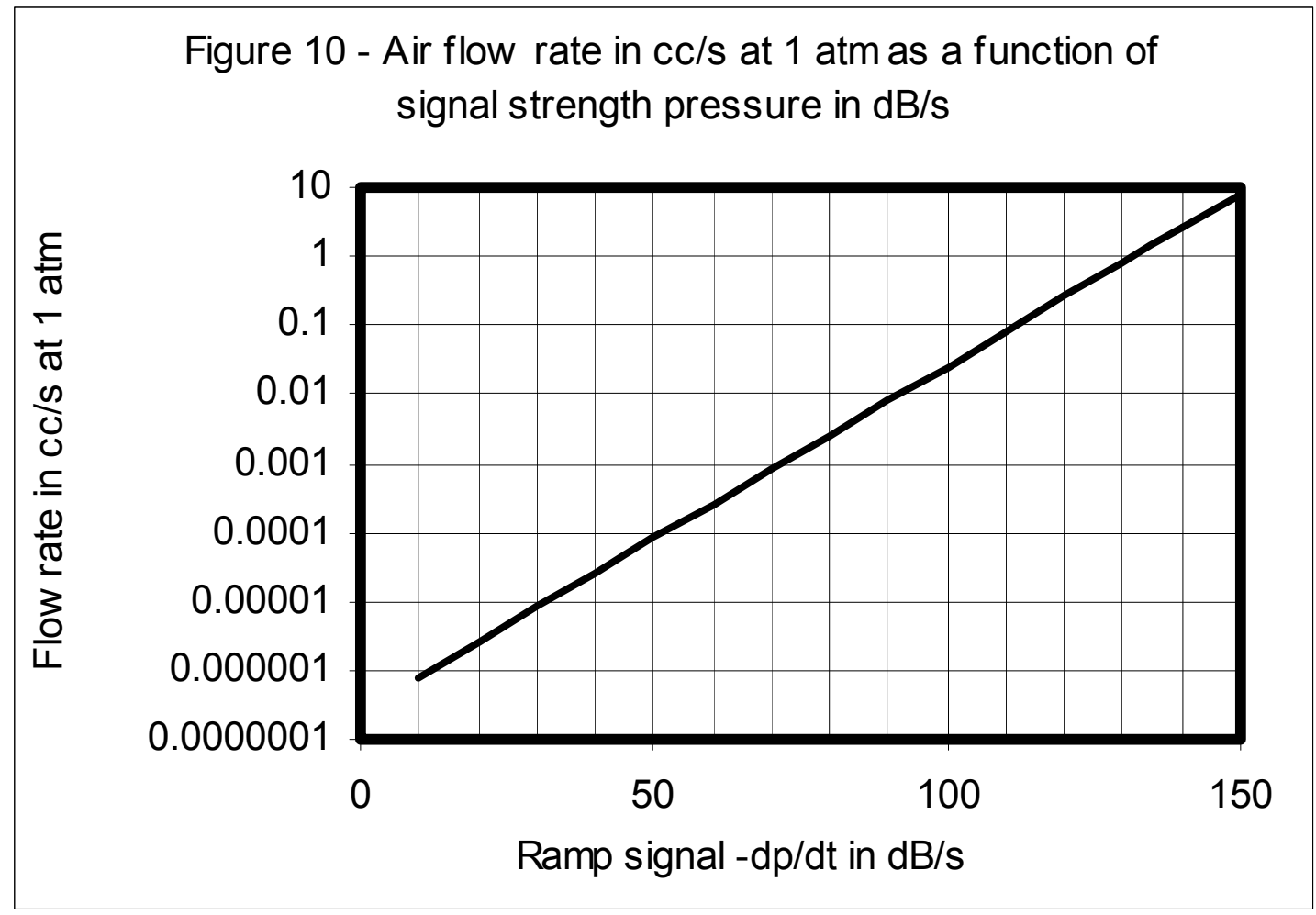

Figure 12 - Air-flow rate vs. dB

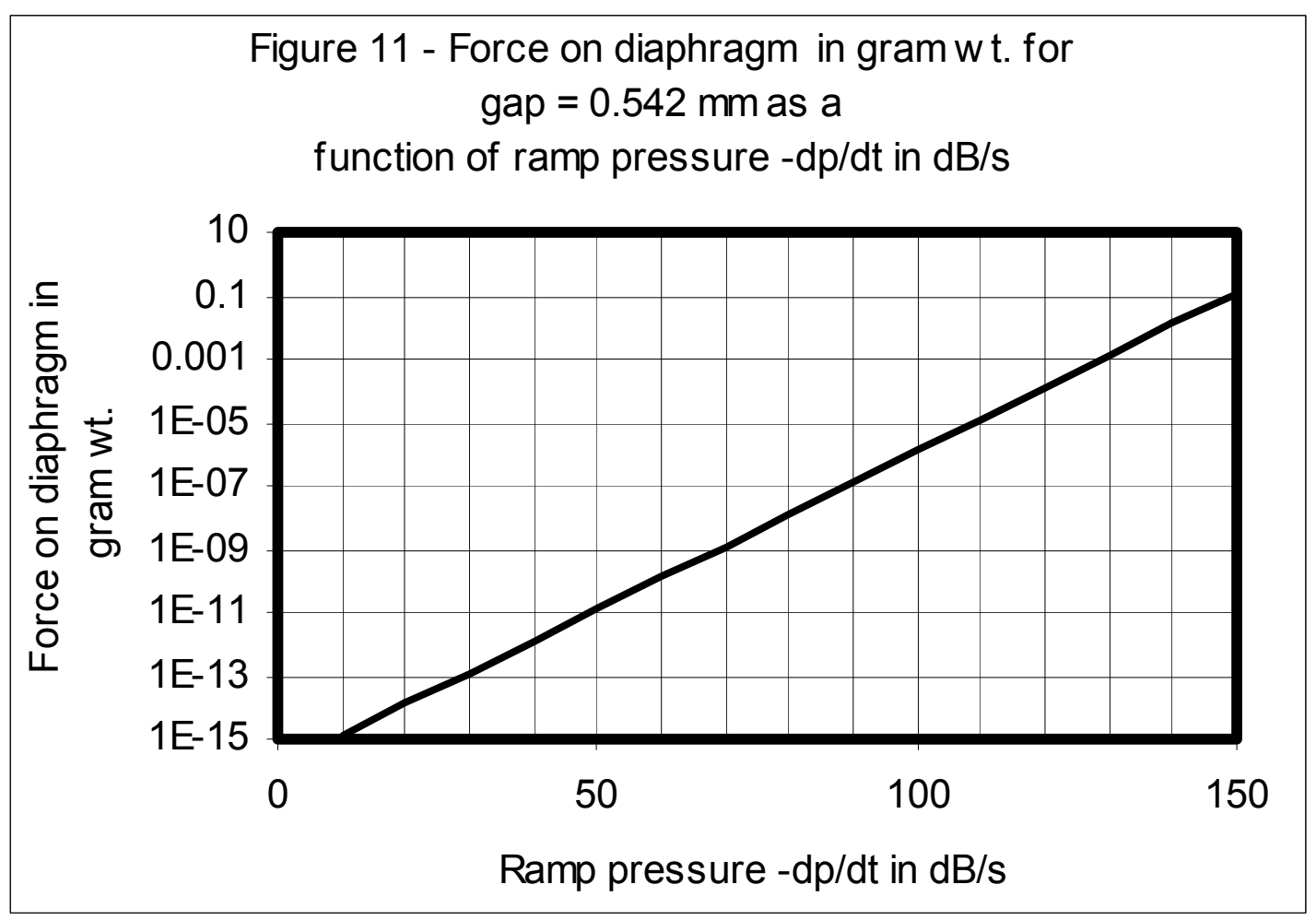

Figure 13 - Diaphragm force vs. - dp/dt 


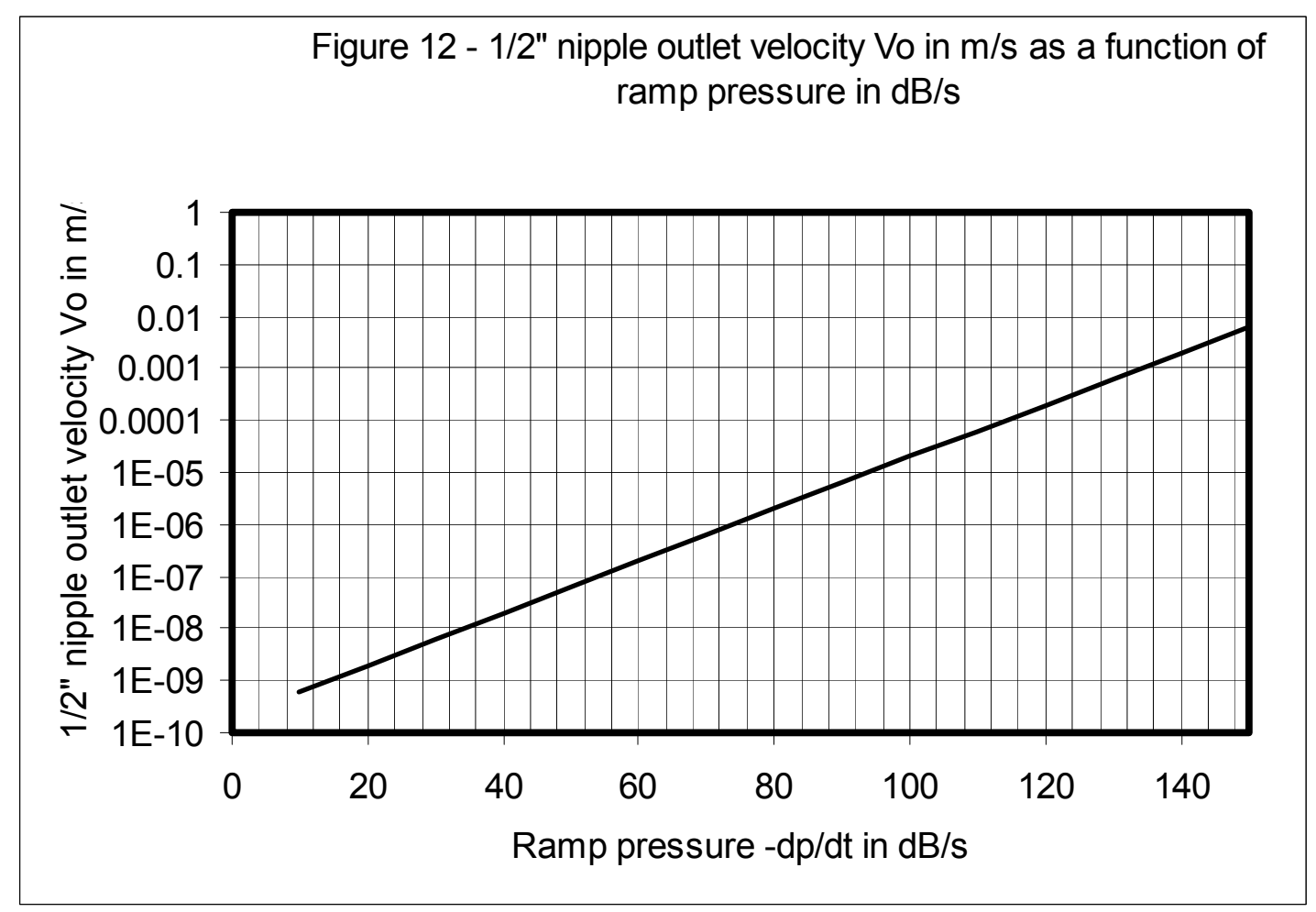

Figure 14 - Outlet velocity vs. $-\mathrm{dp} / \mathrm{dt}$

\section{Report Distribution:}

1) Electronic via CD-ROM in PDF Format, file name 41324R03.pdf Labeled:

DOE Award \# DE-FC26-02NT41324

$3^{\text {rd }}$ Quarter Report

West Virginia University

Dr. John Loth

304-293-4111 ext. 2343

2) One Paper Copy and the above CD-ROM

To:

NETL AAD Document Control BLDG. 921

U.S. Department of Energy

National Energy Technology Laboratory

P.O. Box 10940

Pittsburgh, PA 15236-0940 